\title{
Social Stratification in the Drinking Water Scarcity Context: Empirical Evidence of Coastal Bangladesh
}

\author{
Bishawjit Mallick ${ }^{1,2, *}$, Luisa Fernanda Roldan-Rojas ${ }^{1}$ \\ ${ }^{1}$ Institute of Regional Science (IfR), Karlsruhe Institute of Technology (KIT), Karlsruhe, Germany \\ ${ }^{2}$ Foreign Research Fellow at Political Science Department of Vanderbilt University, Nashville, USA \\ *Corresponding author: bishawjit_mallick@biari.brown.edu, bishawjit.mallick@kit.edu
}

Received June 17, 2015; Revised July 16, 2015; Accepted July 23, 2015

\begin{abstract}
Water is life, but getting safe water is a question of scarcity. In addition, water sources are being affected by extreme weather and climatic events creating pressure on quality of and access to fresh water. Therefore, it is urgent to know what are the easiest and well-managed ways of ensuring drinking water for everyone, how does the social structure influence the water management at community level. This study explores the importance and influence of societal structure in drinking water management. Results show that cconflict arises during the collection of water between the households and within the household and it has impact on the social connectedness and responsibilities of the community people. Initiatives should also be taken, so that the community management process ensure the equality and equity of access to drinking water as a basic human right.
\end{abstract}

Keywords: water scarcity, social structure, coastal livelihood, Bangladesh

Cite This Article: Bishawjit Mallick, and Luisa Fernanda Roldan-Rojas, "Social Stratification in the Drinking Water Scarcity Context: Empirical Evidence of Coastal Bangladesh.” American Journal of Water Resources, vol. 3, no. 3 (2015): 92-99. doi: 10.12691/ajwr-3-3-4.

\section{Introduction}

The availability of safe water sources is one of the basic concerns for human population [1,2,3]. Nowadays there is an increasing trend of water scarcity, which is one of the pressing challenges in different countries around the world. Problems that are related with water availability and water quality are increasing rapidly and have become particularly severe in developing countries, affecting not only the drinking water supply, but also sanitation, food security, economy and transport $[4,5]$. Water problems are not only related to availability or quality, but to water management, which is influenced by social conditions $[6,7]$., As stated by the World Water Forum of 2002, "It is a crisis of managing water so badly, that billions of people and the environment suffer badly and prospects at the longer term look like grim" [8].

There are large variations in water availability, water quality and water management within countries. There are many municipalities in Central and Southern Mexico, Honduras and Nicaragua where less than $10 \%$ of the population have access to drinking water [2]. Also, the poorest and most vulnerable people often end up paying the most for water, as they depend on water purchased from tank trucks, which is often expensive and with a poor quality [9]. This is same case in urban and peri-urban areas in Africa, where "water is often only available from vendors at an unfair price and the quality is often poor" [2]. Similarly, there is unequal access to drinking water throughout the Asian-Pacific region, including "strong contrast between urban and rural areas, and rich and poor households" [2]. In Africa and some Asian regions, water is often carried long distances by women and children [10,11,12].

According to Food and Agriculture Organization of the United Nations [13], there are three main dimensions of water scarcity: (1) Scarcity in availability of water with acceptable quality; (2) Scarcity due to the lack of adequate infrastructure because of financial, technical or other constraints irrespective of the level of water resources; and (3) Scarcity in access to water services, because of the failure of institutions in place to ensure reliable, secure and equitable supply of water to users.

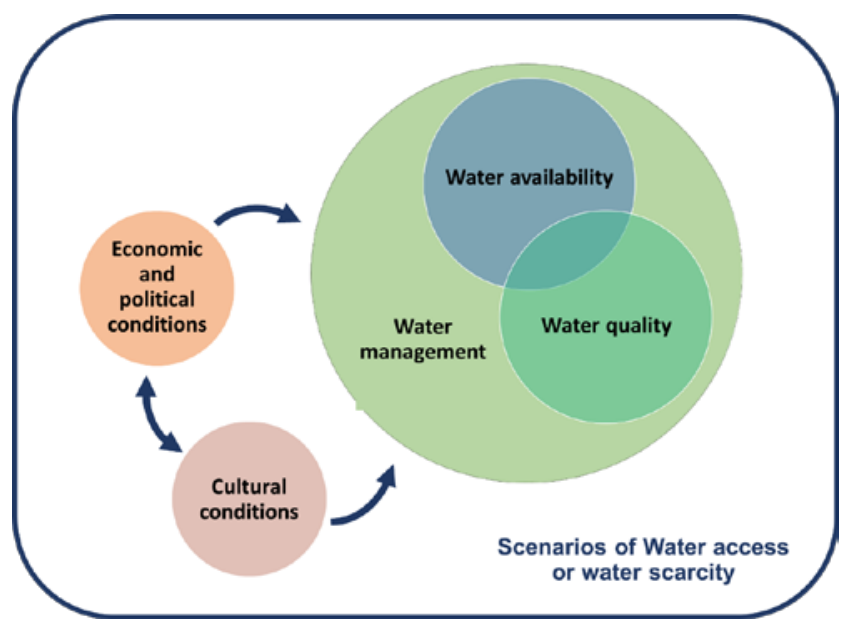

Figure 1. Components of water scarcity assessment. Source: Author's own illustration

Access to safe water also depends on social factors, such as basic hygiene knowledge or social position [14]. 
Social factors affecting access to water supply sources will also determine the ability of people to use safe water [15]. Lower income households may not have access to safe water sources due to cultural norms, which embrace principles of social and local power exercise [16,17] or high income households may be unwilling to share safe water sources with lower income households. Hence, water scarcity is also the result of multiple scenarios of the fluctuation of water management, culture and economic and political conditions (see Figure 1).

\section{Water Scarcity in Bangladesh}

Major determinants behind water crisis in Bangladesh are arsenic, salinity, drought, natural hazards (i.e. flood, cyclone) and decreasing water table [18]. Though the groundwater is plentiful in Bangladesh and is one of the major sources for drinking water supply, salinity and arsenic contamination are higher in groundwater than in other water sources. The Bangladesh Geological Survey 2000 reported that arsenic in ground water exceeded the acceptable limits $(0.05 \mu \mathrm{g} / \mathrm{l})$ in 61 of 64 districts $^{1}$ of the country [19]. National Hydro-chemical survey of 3500 selected deep tubewells ${ }^{2}$ in 2001 found that about 57 million people were drinking water with arsenic concentrations greater than WHO guideline value of $10 \mu \mathrm{g} / \mathrm{l}$ and up to 35 million people used to drink water with arsenic concentrations which exceeded the

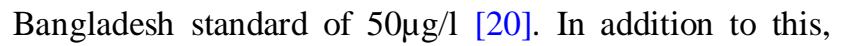
salinity creates water crisis in coastal areas. An investigation of CARE-Bangladesh [21] claimed that 5 million people of 31 upazila $^{3} \mathrm{~s}$ in six southwest coastal districts are facing problems with salinity. S.A. Haque estimated that a total of 1.02 million ha of land of coastal zone is affected by different degrees of salinity [26]. It is evident that salinity arises due to climate change, sea-level rise, and reduction of freshwater flow from upstream. Farakka Barrage ${ }^{4}$ is also responsible for the increasing of salinity in the southwest coastal region (e.g. [22,23]). Natural disasters also play an important role in creating water crisis. The coastal zone of the country is the most disaster-prone; when a disaster occurs, it affects the drinking water sources at first. In this areas, people use to take water usually from ponds, or rain-water harvesting $(\mathrm{RWH})^{5}$ or pond-sand-filter (PSF) ${ }^{6}$, which become

\footnotetext{
${ }^{1}$ District is the $4^{\text {th }}$ tier of local government administration. Actually district level administration control all local government bodies.

${ }^{2}$ Deep Tubewell is promoted in different parts of the country as the deep aquifers have been proved as safe from arsenic contamination. Besides these options can discharge water all the year round [24].

${ }^{3}$ The upazilas are the second lowest tier of regional administration in Bangladesh.

${ }^{4}$ Farakka Barrage is a barrage across the Ganges River, located in the Indian state of West Bengal, roughly 16.5 kilometres from the border with Bangladesh. Construction was started in 1961 and completed in 1975 and this barrage has great impact on the tidal river flows and its management in Bangladesh.

${ }^{5}$ Rainwater Harvesting (RWH) is defined as the process of collecting and storing rain water for future. There is a long-established tradition of rainwater collection in some parts of Bangladesh, where shallow groundwater water has elevated salinity [25].

${ }^{6}$ Pond Sand Filter (PSF) is known as the filtering process of pond water. Hand pumps are used to deliver pond water to the units, which are called Pond Sand Filters (PSF). In this slow sand filtration system a bed of fine sand is used through which the water slowly infiltrate downward, resulting in the removal of pathogens through a combination of physical and biological processes [25].
}

polluted or even being destroyed during natural hazards such as, floods and cyclones. Besides, the declining trends of ground water level adds more pressure on drinking water sources.

Simultaneously, this situation influences the social behavior. CARE-Bangladesh reported that mostly girls and women used to run from village to village for a pitcher of water. They travel at least 2 kilometers to get a pitcher of water. In some villages, 5 or 6 kilometers distance must be traveled to meet the daily demand of drinking-water [21].

The above discussion shows that water management in Bangladesh represents a complex challenge, because it involves not only the analysis of water quality and availability, but also the social conditions. However, there is lack of empirical evidence of how water demand is managed at local level and what roles the community have to ensure safe water for each and every person of their respective community. Aiming at providing further empirical evidence in Bangladesh, this paper identifies the social clusters that influence or even control drinking water management at the local community level.

\section{Materials and Methods}

\subsection{Study Area}

This study took place in Kalikabari village of Morrelgonj Upazila ${ }^{7}\left(22.4500^{\circ} \mathrm{N}, 89.8583^{\circ} \mathrm{E} / 22.4500\right.$; 89.8583) and Jariya Baroidanga village of Fakirhat Upazila $\left(22.7806^{\circ} \mathrm{N}, 89.7083^{\circ} \mathrm{E} / 22.7806\right.$; 89.7083) in Bagerhat district. The total population of Kalikabari village and Jariya Bariodanga village is 2173 and 2670 respectively and average household size is 5.0. The people of the studied villages have been facing problems of having safe drinking water all year round. The department of public health and engineering (DPHE) of Bagerhat district determined that Fakirhat and Morrelgonj are facing drinking water crisis because of arsenic and salinity respectively. Both the surface water storage in ponds and ground water pumped are currently experiencing increasing salinity and arsenic.

In order to meet the daily necessity of safe water, women and children of the families have to carry water for long distance facing various social and physical problems: health hazard, child insecurity, sexual harassment, and quarrel in the family among others.

\subsection{Sample Size and Survey}

Considering the confidence interval of 5 and $95 \%$ confidence level along with $29 \%$ percent of sample picks an answer, a total of 274 household interviews were conducted from the selected two villages (120 in Kalikabari village and 154 in Jariya Baroidanga village). The survey was conducted in 2012.

Based on the conceptual framework presented in Fig. 1, a structured questionnaire was specifically developed for this study, including a sociodemographic section and questions about quality, quantity and access to water

\footnotetext{
${ }^{7}$ Upazila is the $3^{\text {rd }}$ tier of local government administration of Bangladesh. This classification of local government is applied for the rural settlements.
} 
source, perception of social impacts and health hazards due to the drinking water crisis. Questions about other alternatives for drinking water supply in the villages were also included.

In order to analyze a possible socio-demographic classification, the following information was collected: gender, age, household size, monthly income and expenditure, education level and occupation.

To assess the access to a water source, respondents were first asked about the main and alternative sources of drinking water in the area. Sources offered were tubewell, pond, Pond Sand Filter (PSF), Rain Water Harvesting (RWH) or other. Respondents were also asked to estimate the quantity of water that they think they need for the daily activities, and the quantity of water they are able to collect each day. They were also questioned on how many time they need for water collection and how this time consuming affect them. The perceived water quality (1=good, 2=moderate and 3=bad) and reasons for a bad quality were also taken into account.

Furthermore, perceived drinking water crisis was measured by asking respondents to indicate if they think that they are facing a drinking water crisis (yes/no question) and the reasons in the case of a perceived crisis. Reasons offered were content of arsenic, content of salt, drought, and floods. In the case of water consumption from an own tubewell, respondents were asked about the water quality stand and the water consumption, with the aim to identify the water consumption when a source of water is contaminated. Beliefs about social problems due to the drinking water crisis were assessed directly by offering to the respondents the following cases: a) facing different questions in outside, b) feel hesitation to express disease, c) nobody wants to come with me, d) problems to work freely and e)difficult to arrange marriage.

Participants' perception of health hazards was assessed by asking whether respondents think that health hazards occurred due to the drinking water crisis and if they or their families were affected by water-related diseases. As a control question of this perception, respondents were also asked to explain which kind of water-related diseases affected them. Furthermore, to evaluate the reaction on a water-related disease case, respondents indicated if they or their family member had a health treatment, the place of the treatment and its cost, and finally the satisfaction level. The reasons in the case of no treatment were also asked.

\subsection{Analysis Plan}

The analysis plan was structured in three modules: First module covers the analysis of the general profile of respondents; second module focuses on the classification of the respondents according their sociodemographic characteristics, and the third module analyses the sociodemographic classification's and its influence on water management, on the water consumption related behavior and on perception of social impacts and health hazards.

\section{Results and Discussion}

\subsection{General Profile of Respondents}

The basic socio-demographic finding is presented in Table 1 . In the village Kalikabari, the average age was 41
$(\mathrm{SD}=15)$ and $68 \%$ were male; the average household members was $4(\mathrm{SD}=1)$. For the village Jaria Baroidanga, these values were: average age $43(\mathrm{SD}=12), 86 \%$ were male and the average household members was $5(\mathrm{SD}=1)$. The data of both villages was analyzed as a whole with the aim to develop a valid social classification not only for a village but for the country also. For both villages, the mean age of the respondents was 42 years $(\mathrm{SD}=14)$ and $76 \%$ were male; household size widely varies between 1 to 8 members; with an average household size of 5 $(\mathrm{SD}=1)$, which is near to the national average household's size. The national average household size in Bangladesh is 4.8 [27].

Table 1. Respondents' education level, occupation and income (given in percentage)

\begin{tabular}{|c|c|c|c|c|}
\hline & $\begin{array}{l}\text { Socio-demographic } \\
\text { characteristic }\end{array}$ & $\begin{array}{c}\text { Both } \\
\text { Villages }\end{array}$ & $\begin{array}{c}\text { Jariya } \\
\text { Baroidanga }\end{array}$ & Kalikabari \\
\hline \multirow{4}{*}{ 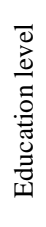 } & Illiterate & 43 & 27 & 63 \\
\hline & Under SSC & 32 & 41 & 20 \\
\hline & Under HSC & 19 & 27 & 8 \\
\hline & HSC or higher education & 7 & 5 & 9 \\
\hline \multirow{5}{*}{ 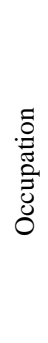 } & Homemakers & 22 & 28 & 14 \\
\hline & Agricultural sector & 58 & 51 & 67 \\
\hline & Business owners & 11 & 14 & 6 \\
\hline & $\begin{array}{l}\text { Employees of } \\
\text { Government or no- } \\
\text { Government institutions }\end{array}$ & 8 & 5 & 12 \\
\hline & Other & 2 & 1 & 2 \\
\hline \multirow{5}{*}{$\begin{array}{l}\underset{\dot{\vec{g}}}{E} \\
\stackrel{\Xi}{\Xi} \\
\stackrel{\Xi}{\Xi}\end{array}$} & $3000-4000$ & 46 & 31 & 68 \\
\hline & $4001-5000$ & 39 & 53 & 22 \\
\hline & $5001-6000$ & 7 & 8 & 6 \\
\hline & $6001-7000$ & 3 & 4 & 0 \\
\hline & $>7000$ & 5 & 4 & 5 \\
\hline
\end{tabular}

Source: Field survey 2012

Differences between the education levels and occupations of the respondents (Table 2) in the two villages show the diversity between the villages, what raises the clustering of sample with the aim of find out the integrity/differences between different social classes. The monthly income of $85.5 \%$ of the respondents lies under 5000 BDT (1 US\$ $=78$ BDT) that is comparatively lower than national average monthly income. The national average monthly income in Bangladesh is 7,203 BDT and the rural monthly household income is 6,095 BDT [27]. For the study villages, a monthly income of 5,000 BDT represents a limit between two economic classes.

\subsection{Socio-demographic Classification}

At first, the socio demographic characteristics (i.e. gender, age, household size, monthly income and expenditure, education level and occupation) were correlated, in order to determine which characteristics were showing associations between them.

The results shows a higher level association between monthly income and expenditure $\left(\mathrm{R}^{2}=0.933\right)$. Both of this variable were then taken into consideration for clustering. 
Another representative correlation (Cramers V=0.961) was found between gender and occupation. However, $90.9 \%$ of the women were housewives; it indicates that there is a social division of occupation pattern, therefore, occupation and gender of the respondent were taken into account gender for the social clustering.

In addition, education level and occupation have a moderate correlation (Cramers $V=0.482$ ), both of them were taken into clustering process. Furthermore, education level has not a gender division as by occupation.

Demographic characteristics, like age and household size did not correlate significantly with the other variables, and were therefore not included in the clustering.
Based on this analysis, the significant sociodemographic characteristics for a clustering are: monthly income and education level. They showed internal consistency and reasonable distribution in the current sample.

Secondly, two-step cluster analysis with the monthly income and education level was carried out using SPSS Software. The optimal number of clusters was 3 with a Silhouette measure of cohesion and separation of 0.4 , what means a fair cluster quality. The distribution of respondents' education level and income level are show in Table 2 and Table 3 respectively.

Table 2. Respondents' education level pro cluster

\begin{tabular}{|c|c|c|c|c|c|c|c|c|c|c|c|c|c|}
\hline & & \multicolumn{2}{|c|}{ Illiterate } & \multicolumn{2}{|c|}{ Under SSC } & \multicolumn{2}{|c|}{ SSC } & \multicolumn{2}{|c|}{ Under HSC } & \multicolumn{2}{|c|}{ HSC } & \multicolumn{2}{|c|}{$\begin{array}{l}\text { Undergraduate and } \\
\text { graduate }\end{array}$} \\
\hline & & Frequency & Percent & Frequency & Percent & Frequency & Percent & Frequency & Percent & Frequency & Percent & Frequency & Percent \\
\hline \multirow{3}{*}{ 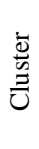 } & 1 & 0 & $0,0 \%$ & 81 & $93,1 \%$ & 0 & $0,0 \%$ & 0 & $0,0 \%$ & 0 & $0,0 \%$ & 0 & $0,0 \%$ \\
\hline & 2 & 0 & $0,0 \%$ & 6 & $6,9 \%$ & 40 & $100,0 \%$ & 11 & $100,0 \%$ & 10 & $100,0 \%$ & 8 & $100,0 \%$ \\
\hline & 3 & 118 & $100,0 \%$ & 0 & $0,0 \%$ & 0 & $0,0 \%$ & 0 & $0,0 \%$ & 0 & $0,0 \%$ & 0 & $0,0 \%$ \\
\hline
\end{tabular}

Source: Field survey 2012.

Table 3. Respondents' monthly income level pro cluster

\begin{tabular}{|c|c|c|c|c|c|c|c|c|c|c|c|}
\hline & & \multicolumn{2}{|c|}{$3000-4000$} & \multicolumn{2}{|c|}{$4001-5000$} & \multicolumn{2}{|c|}{$5001-6000$} & \multicolumn{2}{|c|}{$6001-7000$} & \multicolumn{2}{|c|}{$7000+$} \\
\hline & & Frequency & Percent & Frequency & Percent & Frequency & Percent & Frequency & Percent & Frequency & Percent \\
\hline \multirow{3}{*}{ 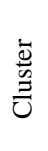 } & 1 & 38 & $29,9 \%$ & 43 & $40,2 \%$ & 0 & $0,0 \%$ & 0 & $0,0 \%$ & 0 & $0,0 \%$ \\
\hline & 2 & 11 & $8,7 \%$ & 24 & $22,4 \%$ & 19 & $100,0 \%$ & 7 & $100,0 \%$ & 14 & $100,0 \%$ \\
\hline & 3 & 78 & $61,4 \%$ & 40 & $37,4 \%$ & 0 & $0,0 \%$ & 0 & $0,0 \%$ & 0 & $0,0 \%$ \\
\hline
\end{tabular}

Source: Field survey 2012.

By analyzing Table 2 and Table 3, the following four groups were distinguished:

- Group 1 (low) includes illiterate people and those who have a monthly income up to 5000 BDT. This group is classified as low by the socio-demographic classification because it includes people with no education level and low monthly income.

- Group 2 (medium-low) is formed by 93\% of respondents with an education level under SSC are included in this cluster, and all of them have also a monthly income up to $5000 \mathrm{BDT}$. This group is classified as medium-low by the socio-demographic classification because it includes people with poor education level (under SSC) and low monthly income.

- Group 3 (medium-high) corresponds the respondents with an education level over SSC and income up to 5000 BDT. Although the respondents' income is up to $5000 \mathrm{BDT}$, these respondents can have better chances in the future because of their education level
(SSC and higher). The socio-demographic classification for the group is medium-high.

- Group 4 (high) means the respondents with an education level of SSC and higher, and income over 5000 BDT.

A resume of the sociodemographic classification in the research area is show in Figure 2.

By contrasting the immediate milieu of occupations with the developed socio demographic classification in the research area, it has been demonstrated that the classification is appropriated for the socio demographic classification in Bangladesh (Table 4). Most of the respondents (i.e. business owners and employees of government or no-government institutions) who influence on the decision making process of the society belong to the elite in Bangladesh (i.e. socio demographic class 4). Housewives and workers in the agricultural sector and farmers were included, belong to the three first socio demographic classes, most of them to the first class.

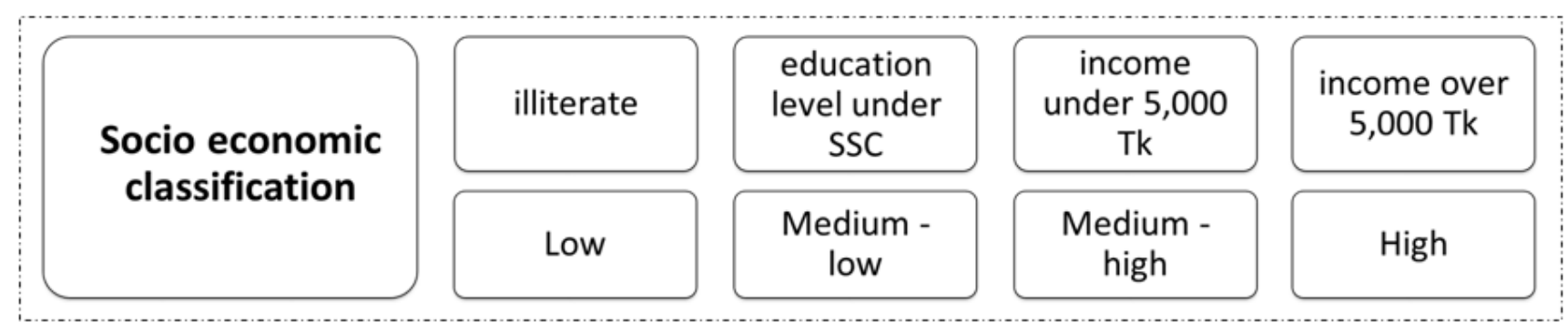

Figure 2. Socio demographic classification methodology for Bangladesh. Source: Authors’ own illustration 
Table 4. Distribution of milieu of occupations and socio demographic classification in the research areas

\begin{tabular}{|c|c|c|c|c|}
\hline \multirow{2}{*}{ Milieu of occupations } & \multicolumn{4}{|c|}{ Socio demographic classification } \\
\cline { 2 - 5 } & low & Medium-low & Medium-high & High \\
\hline Housewives & 27 & 27 & 6 & 0 \\
\hline Agricultural sector & 91 & 51 & 1 & 23 \\
\hline Business owners & 0 & 5 & 9 & 11 \\
\hline Employees of Government or no-Government institutions & 0 & 2 & 2 & 0 \\
\hline Other & 0 & 2 & & 0 \\
\hline
\end{tabular}

Source: Field survey 2012.

\subsection{Existing Water Sources}

There are not too many main water sources for drinking purpose: most of the participants from Jariya Baroidanga use tubewells (64\%) and a remaining 36\% uses pond, while in Kalikabari there is only Pond Sand Filter (PSF) as water source. This indicates that the use of a water source depends on its availability: In the case of one available water source, the socio demographic classification do not influence who uses it; but in the case of two or more available water sources in the same region or village, it was observed, that the use of unsafe water sources decreases with a higher socio demographic class (see Table 5). This is the case in the village Jariya Baroidnaga, where water from pond is used by participants who belong to the three classes (see Table 5). Therefore, there is a tendency to use unsafe water for domestic and drinking purpose when people do not have a middle or high education level (see Figure 2). Higher dependence of the people on pond water also indicates a high risk of spreading waterborne diseases due to use of unsafe pond water.

Table 5. Respondents' socio demographic classes and access to water source

\begin{tabular}{|c|c|c|c|c|c|c|c|}
\hline \multirow{2}{*}{$\begin{array}{l}\text { Socio- } \\
\text { demographic } \\
\text { classification }\end{array}$} & \multirow{2}{*}{$\frac{\text { Water source }}{\text { Time measure for collecting water }}$} & \multicolumn{2}{|c|}{ Tubewell } & \multicolumn{2}{|c|}{ Pond } & \multicolumn{2}{|c|}{ PSF } \\
\hline & & $<30 \min$ & 30 to $60 \mathrm{~min}$ & $<30 \min$ & 30 to $60 \mathrm{~min}$ & $<30 \min$ & 30 to $60 \mathrm{~min}$ \\
\hline \multirow{3}{*}{ Low } & Average distance to the water source (m) & 359 & 1,132 & 311 & 1,075 & 514 & 847 \\
\hline & SD & 124 & 159 & 111 & 337 & 35 & 230 \\
\hline & Number of respondents & 11 & 11 & 14 & 6 & 22 & 54 \\
\hline \multirow{3}{*}{ Medium-low } & Average distance to the water source (m) & 296 & 1,052 & 228 & --- & 446 & 883 \\
\hline & SD & 182 & 263 & 123 & --- & 147 & 272 \\
\hline & Number of respondents & 21 & 24 & 18 & 0 & 12 & 12 \\
\hline \multirow{3}{*}{ Medium-high } & Average distance to the water source (m) & 157 & 1,304 & 400 & 1,233 & 276 & 900 \\
\hline & SD & 105 & 224 & 0 & 115 & 208 & 424 \\
\hline & Number of respondents & 9 & 12 & 2 & 3 & 7 & 2 \\
\hline \multirow{3}{*}{ High } & Average distance to the water source (m) & 319 & 750 & --- & --- & 139 & 600 \\
\hline & SD & 176 & 0 & --- & --- & 155 & 0 \\
\hline & Number of respondents & 20 & 3 & 0 & 0 & 10 & 1 \\
\hline
\end{tabular}

Source: Field survey 2012.

\subsection{Perception of Water Crisis and Water Management}

By analyzing the access to the water sources, Table 4 shows the influence of socio-demographic class: high class has an average distance to the water source lower than the others classes; however it is not the case for collecting water from a tubewell for up to 30 minutes, what shows the vulnerability of all respondents, regardless of socio-demographic class. They are vulnerable according to Howard and Bartraum [28], who declared a very high level of health concern for people who need to walk more than $1000 \mathrm{~m}$ to the water source or 30 minutes total collection time.
About $81 \%$ respondents mentioned that they do not get sufficient water. Level of health concern is also affected by the likely quantities collected, which in the research villages was very low with an average of $4 \mathrm{l} / \mathrm{c} / \mathrm{d}(\mathrm{SD}=1)$. Therefore, the respondents in the two villages belong to the "no access group" as "the quantities collected are low, the effort taken to acquire water is excessive and quality cannot be assure” [28].

The water quality cannot be assured on the one hand due to the use of vessels for the water transport which can be contaminated or do not protect the water during the transport. On the other hand, it is observed that participants are not satisfied with the water quality. Most of them classify the water quality as "more or less good" and "bad" (see Figure 3). 97 of the 104 Respondents who considered the water quality as "bad" based it on the fact 
that water contains arsenic (tubewells and ponds) or salt (each user of PSF affirmed that the water is contaminated with salt). Odor was identified as an indicator for bad water quality, however only 7 participants considered it.

63 of the 111 participants who use tubewell as water source had an own tubewell, although 36 tubewell are contaminated with arsenic. Users of ponds and PFSs had also an own tubewell, 26 and 9 respectively. 16 tubewells of pond users are affected by arsenic, while tubewells of PSF users are not. Thus, the village Jariya Baroidanga is facing a water quality problem regarding a high probability of arsenic contamination by use of groundwater. Another issue of concern is the use of water contaminated with arsenic for domestic and drinking purpose (17 and 14 respondents, users of tubewells and ponds respectively).

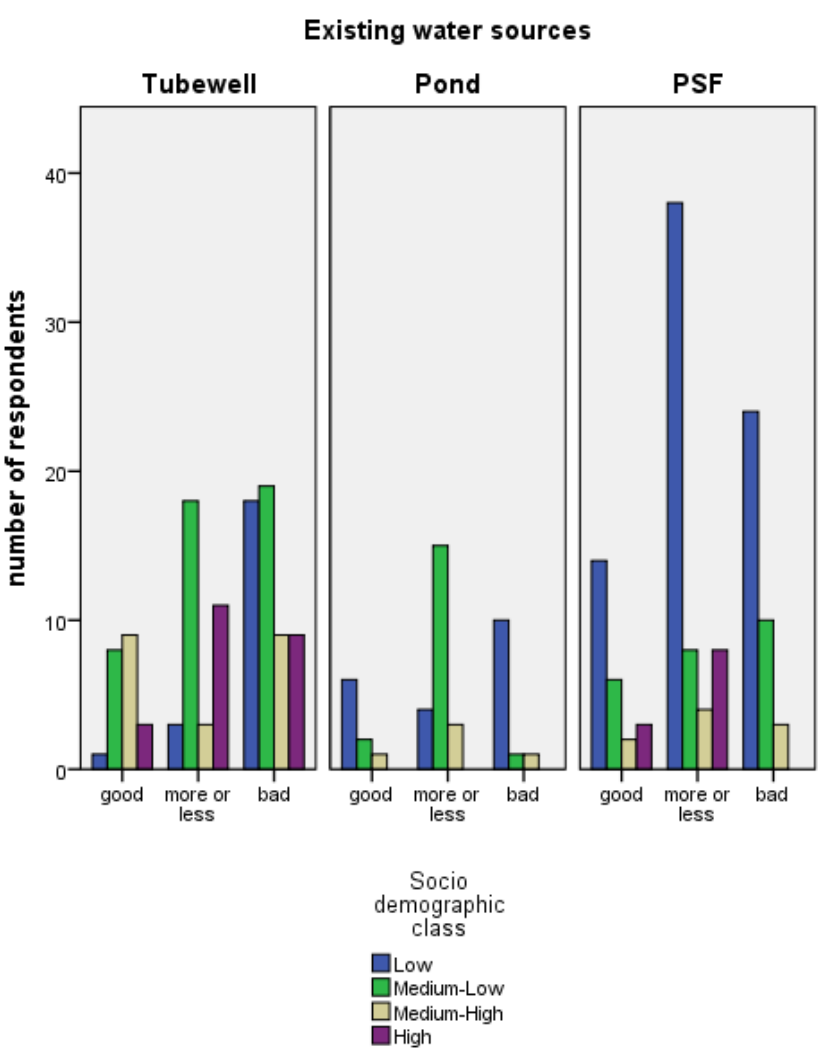

Figure 3. Respondents' perception of water quality (Source: Authors' illustration based on field survey 2012)

To the question "Do you think that you are facing a drinking water crisis? most of the participants (89\%) answered ,yes'. In the village Jariya Baroidanga, 100\% of the respondents think that they are facing a drinking water crisis, and in the village Kalikabari, $80 \%$ of the respondents agreed that there is a drinking water crisis in the village. A reason for the drinking water crisis is that water contains arsenic or salt. To mitigate the drinking water crisis, respondents mentioned different measures:

Reinstallation of tubewells is not easy due to high cost and lack of trained data collected. The village Jariya Baroidanga has the problem that water contains arsenic which indicates that the aquifer is in contact with arsenic deposit. An investigation of the groundwater quality or aquifers must be thus performed before reinstall or shifting a tubewell. This answer indicates also on the one hand that tubewells are perceived as water supply points and not as a part of the nature. On the other hand, respondents do not have knowledge about the groundwater cycles and how geological conditions affect the water quality.

Awareness campaigns about how to improve and manage the water supply. This indicates that respondents would have perceived that drinking water crisis is a question of accessibility to a safe water source and awareness development as well.

Improvement of health facilities. The survey indicates that respondents perceived, on the one hand a lack of the health facilities quantities, or on the other hand, a low access to the actual health facilities.

Water filtration. This measure was mentioned only by the PSF's users (107 of 120).

From this study, it was found that $72 \%$ of the respondents perceive a link between the drinking water crisis and the occurrence of health hazards. It was also observed, that $71 \%$ of the participants affirmed that they or a member of their family was affected by a waterrelated disease. Mentioned water-related diseases were arsenicosis and diseases by the liver, respiratory system and skin. Water-borne diseases were not mentioned, which could mean that such as diseases do not occur in the villages or that there was no awareness campaign on this topic in the study villages, what was not part of this investigation but it is also important to research.

About $80 \%$ of the respondents mentioned that their family members had a medical treatment for a waterrelated disease. Among them, most of the people (66\%) used the services of a village doctor, $16 \%$ an Upazila Health Complex, 12\% a NGO's Health Center and 7\% a Health Clinic. Financial problems and lack of proper medical facilities were cited by the respondents, who did not have a medical treatment.

Drinking water crisis introduces not only health hazards but social impacts too. This was identify by $88.7 \%$ of the respondents. Mentioned social problems by them were (see Figure 3):

- Being shamed and facing different questions outside their community. The perception of this social problem increases with the socio demographic class.

- Feeling hesitation to express diseases. The perception of it decreases with the socio demographic class.

- Having problems to work freely. There is a tendency for the first three socio-demographic classes: people's perception of this social problems decreases with the socio demographic class. But this social problems is important for the class four.

- Feeling isolated from the community as nobody wants to have contact with them.

The respondents were facing different problems related with drinking water collection outside their community. The perception of this social problem increases with the socio-demographic class. For example, none of the first three socio-demographic classes were comfortable to contact each other to discuss their diseases. Such kind of social problem is not important for the high class (Fig. 4).

The available data of this study also indicates that they villagers invested time in water collection, and therefore the long-distance travel each and every day, introduces sometimes social and family problems. Part of the housewives' work is to collect drinking water for the family by carrying the collected water by themselves. Therefore, the time for other housewives' works decreases, 
what is identified as a negative effect (49\%). Time for water collection increases also conflicts between family members (38\%) and reduces the monthly income (12\%).

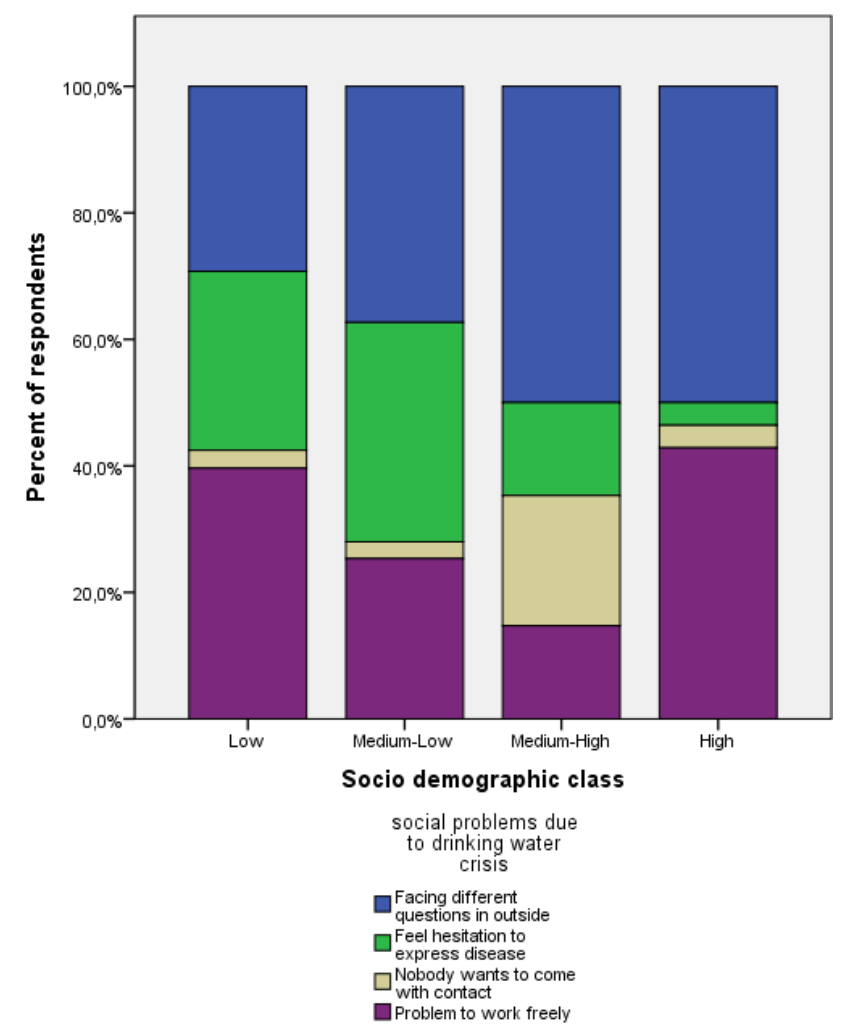

Figure 4. Respondents' perception of social problems (Source: Authors' own illustration based on field survey 2012)

Conflict arises during the collection of water between the households and within the household. It was reported that people collect their drinking water from long distance. In most cases it is done by the housewife. It takes huge time as the safe drinking water sources are in far distance and kill the precious time of housewife. As a result sometimes quarrel is taken place between the family members. Due to drinking contaminated water people are facing different types of health hazards and sometimes they feel hesitation to express their diseases to their relatives and doctors. Sometimes people don't want to come in contact with the affected people. So they can't move freely here and there. This scenario represents the extent of drinking water crisis of the study.

The next section describes how the results of this research can be translated into planning and action for the betterment of drinking water management in the study villages.

\section{Conclusion and Outlook}

Drinking water quality is worseningday by day due to arsenic and salinity in the study areas which keep increasing and have already exceed the drinkable limit guided by WHO and Government of Bangladesh. In spite of this, most of the people remainusing contaminated water except for drinking purpose and in sometimes even for all purposes. In addition to this unsafe drinking water issues the shortage is more acute in the study areas. It is known that water comes from two main sources: ground source and surface sources. Salinity in surface water is constantly increasing in the study areas creating an enormous pressure on the agricultural production. Due to higher salinity in water, agricultural production is decreasing. As a result the income decreases causing people to shift their occupation pattern. Beside these economic problems, people are also facing different social issues. In the course of the study it was exposed that many people are confronting different types of health hazards as skin disease and arsenicosis are more prominent diseases.

This paper provides an overview of drinking water crisis in the study areas. People's living standard is worsening day by day. Available supply of drinking water sources are inadequate to support the present demand of the community as well. Moreover, these water sources are not functioning properlydue to technical problems, absence of management. Drinking water crisis in the study areas is, indeed, severe and requires extending the knowledge and capacity. The effects of disaster on drinking water sources in this study region have attracted many NGOs to start working on drinking water problems. After the devastation caused by cyclone Sidr (2007) and cyclone Aila, (2009) NGOs distributed potable water during emergency as well as the distribution of tanks for rainwater harvesting [16]. They built community structures such as PSFs and dug deep tube wells. Cyclone Aila, especially, has been a wakeup call as a large number of ponds were flooded with seawater, destroying a vital source. It resulted in a intensified awareness of the vulnerability of these populations and the need to find solutions [16]. However, after the NGO withdraw their supports, those community infrastructures were no longer in operation, the community hardly took any initiative to keep them running [16]. This community behavior reveals the importance of assessing and developing aid programs. Additionally, it illustrates the community cohesion and collaborative action in general. Both of these issues should be considered for the future preparation of plans.

Drinking water crisis is not peculiar to Bangladesh alone. It is a global problem. There are other countries in the world that had experienced or are facing this problem. The great difference is the degree and extent of the environmental disasters in Bangladesh, since the number of people at risk is higher than other countries. It is enviable that this paper can be an input into further planning and decision making to mitigate drinking water crisis in Bangladesh. This study provides some recommendations to reduce the health and socio-economic consequences of drinking water crisis in the study areas. These recommendations may not be the right solutions to address those problems, since more scientific, economic and social studies are required for reducing the current drinking water crisis. Unfortunately, the people in the study areas in Bangladesh are still unaware of the drinking water crisis and its hazardous effects. The governmental efforts have shown to be far from sufficient to reduce the crisis. The NGOs should embrace more holistic approaches that ensure the community integrity and participation, so that the community will lead and continue the project even after the end of external funding. Hence, the immediate involvement of local, regional and also international community is urgent to combat the slow onset disaster and save the poor people. Initiatives should also be taken, so that the community management process 
ensure the equality and equity of access to drinking water as a basic human right.

\section{Study Competing Interest}

The authors declare that they have no competing interests.

\section{Acknowledgements}

The authors are grateful to the four field assistants: Sudeb Roy, Utpal Das, Sk. Shahidul Islam and Nazrul Islam for their hard work during field surveys and data input. The authors are grateful to Ms. Gabriela Ponce Guerrero, a master's student of environmental science at ETH Zurich, Switzerland for her supports during revisions and editing of the manuscript.

\section{References}

[1] Gleick, P.H., "Basic water requirements for human activities: Meeting Basic Needs", Water International, 21 (2), 83-92, 1996.

[2] World Water Assessment Programme [WWAP], The United Nations World Water Development Report 4: Managing Water under Uncertainty and Risk, United Nations Educational, Scientific and Cultural Organization, Paris, 2012.

[3] World Health Organization [WHO] and UNICEF, Progress on sanitation and drinking-water - 2014 update, WHO Press, Geneva, 2014.

[4] Faisal, I.M. \& Kabir, M.R An Analysis of Gender-Water Nexus in Bangladesh, Journal of Developing Societies, Vol. 21(1-2): 175194, 2005.

[5] Paavola, J. Livelihoods, vulnerability and adaptation to climate change in Morogoro, Tanzania. Environmental Science \& Policy 11(7), 642-654, 2008.

[6] Anand PB, Scarcity, entitlements and the economics of water in developing countries, Cheltenham: Elgar, 2007.

[7] Banwell C., Stanley U., Dixon J., When Culture Impacts Health:Global Lessons for Effective Health Research, Academic Press, 2013.

[8] Cosgrove, W.J., Rijsberman, F.R., Making Water everybody's Business, Earthscan Publications Ltd, London, 2000.

[9] United Nations Environment Programme [UNEP], Global Environment Outlook: Latin America and the Caribbean (GEO LAC) 3. United Nations Environment Programme, Regional Office for Latin America and the Caribbean. Panama City, 2010.

[10] Water and Sanitation Program [WSP], Gender in Water and Sanitation, Nairobi, 2010.

[11] UN Water, Gender, Water and Sanitation: a Policy Brief, United Nations, New York, 2006.
[12] Women in Eurpoe for a Common future [WECF], Water and Sanitation from a gender perspective at the world Forum 4, Mexico, 13-21 March, Ultrecht/Munich, 2006.

[13] Food and Agriculture Organizaiton of the United Naitons [FAO], Coping with water scarcity: An action framework for agriculture and food security, Water Reports 38, Rome, 2012.

[14] Donohue, Styles, Coxon, \& Irvine, Importance of spatial and temporal patterns for assessment of risk of diffuse nutrient emissions to surface waters, Journal of Hydrology, 304, Issues 1-4 10:183-192, 2005.

[15] Roldan-Rojas, L.F., Megerle, A., Perception of Water Quality and Health Risks in the Rural Area of Medellín, American Journal of Rural Development, 1(5), 106-115, 2013.

[16] Sarkar, R. "Die Vulnerabilität der Trinkwasserversorgung im ländlichen Küstenraum von Bangladesch bei und nach Extremereignissen", Masters Thesis, Institute of Regional Science, Karlsruhe Institute of Technology, Germany. 2011.

[17] Mallick \& Vogt, Coastal Livelihood and Physical Infrastructure in Bangladesh after Cylcone Aila, Mitigation and Adaptation of Strategies for Global Change, 16(6), 629-648, 2011.

[18] Takagi et al., Perfluorooctanesulfonate and perfluorooctanoate in raw and treated tap water from Osaka, Japan, Chemosphere, Vol. 72, Issue 10:1409-1412, 2008

[19] Alam, A. M. S., Islam, M. A., Ahmed, E., Islam, S., Siddique, M. N. A., Matin, M. A., Samad, M. A. and Quayum, M. E., Study of the role of arsenic in water resources in Bangladesh, International Seminar on Strengthening Capacity in Developing Countries for Water Resources Research. International Foundation for Science. Stockholm, Sweden, 2003.

[20] BGS and DPHE, Arsenic contamination of groundwater in Bangladesh, 2001.

[21] CARE Bangladesh, How can we drink saline water?, Advocacy campaign of the " Pani Committee" (Water Committee), 2007. [Online]. Available: http://www.carebd.org. [Accessed Jun. 17, 2015].

[22] Mirza, M.K. Diversion of the Ganges Water at Farakka and Its Effects on Salinity in Bangladesh, Environmental Management Vol. 22(5): 711-722, 1998.

[23] Mirza, M.K. Vulnerability to the Ganges Water Diversion: Adaptation and Coping Mechanisms, in Mirza, M.K. (ed.): The Ganges Water Diversion: Environmental Effects and Implications, Water Science and Technology Library Volume 49: 247-285, 2004.

[24] NGO Forum, Annual Report 2007.

[25] Jakariya, M., Rahman, M., Chowdhury, A. M. R., Rahman, M., Yunus, M., Bhiuya, A., Wahed, M. A., Bhattacharya, P., Jacks, G., Vahter, M. \& Persson, L.-Å., Sustainable safe water options in Bangladesh: Experiences from the Arsenic Project at Matlab, London, 2005.

[26] Haque, S.A. Salinity problem and crop production in Coastal regions of Bangladesh, Pakistan Journal of Botany, 38(5), 13591365, 2006.

[27] BBS. Statistical Year Book, Bangladesh Bureau of Statistics, Government of Bangladesh. 2011.

[28] Howard, G., Bartram, J., Domestic Water Quality, Service, Level and Health, WHO, 2003. 